\title{
Outpatient Colonoscopy by Rural Family Physicians
}

\author{
Robert J. Newman, $M D^{1}$ \\ David B. Nichols, $M D^{2}$ \\ Doyle M. Cummings, PharmD ${ }^{1}$ \\ 'Brody School of Medicine, East Carolina \\ University, Greenville, NC \\ ${ }^{2}$ Private practice, White Stone, Va

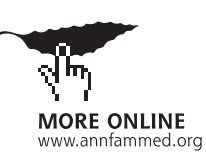

Conflicts of interest: none reported

\section{CORRESPONDING AUTHOR}

Robert J. Newman, MD

600 Moye Boulevard

Brody School of Medicine

Greenville, NC 27834

newmanr@mail.ecu.edu

\begin{abstract}
PURPOSE Five percent of family physicians offer colonoscopy services, either in the office or the hospital, often in rural areas that have no gastroenterologist. Two previous large series have shown the quality and safety of colonoscopy performed by family physicians. The purpose of this study was to verify these findings in an outpatient setting, as well as to obtain patient satisfaction data.
\end{abstract}

METHODS Data were obtained from 731 colonoscopies performed between 1996 and 2001 in a rural Virginia family practice. These data included patients' age and sex, indications for the procedure, drug dosages for sedation, cecal intubation rates, pathologic findings, complications, and referral correlation findings compared with the original examimation. A patient satisfaction survey was done.

RESULTS The adenoma detection rate was $27.2 \%$ for men and $21.4 \%$ for women older than age 50 years. Six adenocarcinomas and 5 large $(>2 \mathrm{~cm})$ villous adenomas were detected, and the patients were referred for definitive surgical resection. A total of 29 patients (4\%) were referred: 10 to colorectal surgery and 19 to gastroenterology for resection of large polyps. Correlation of findings at referral with the initial examination was excellent. Cecal intubation rates increased from 89.5\% from 1996-1998 to $94.6 \%$ from 1999-2001. Minor sedation complications occurred in 5 cases $(<1 \%)$, and patients responded to supportive care. A high degree of satisfaction was reported by patients, with a mean satisfaction score of 8.8 on a scale from 1 to 10 .

CONCLUSIONS Colonoscopy can be performed safely and competently by properly trained family physicians in an outpatient setting with a high degree of patient satisfaction.

Ann Fam Med 2005;3:122-125. DOI: 10.1370/afm.268.

\section{INTRODUCTION}

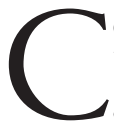

olorectal cancer is the second leading cause of cancer death in the United States ${ }_{i}$ in 2001 there were 135,400 new cases diagnosed and 56,700 deaths from this disease. ${ }^{1}$ Despite recommendations for colorectal cancer screening by the American College of Gastroenterology, the US Preventive Services Task Force, and the American Cancer Society, only $33.6 \%$ of eligible patients in 1999 had undergone screening sigmoidoscopy or colonoscopy in the preceding 5 years. ${ }^{2}$ Barriers to this screening are many, but certainly an inadequate number of trained colonoscopists, particularly in rural areas, is a major factor. ${ }^{3}$

Five percent of family physicians offer colonoscopy services to their patients, ${ }^{4}$ and $2 \%$ of colonoscopies $(23,841)$ billed to Medicare in 1993 were done by family physicians. ${ }^{5}$ Specialty-neutral hospital credentialing policies, based on proven training and competence, have been advocated by the American Medical Association, the Joint Commission of Accreditation of Health Care Organizations, and the American Academy of Family Physicians. ${ }^{6}$ Even so, some family physicians have had difficulty obtaining colonoscopy privileges, especially in physician-dense areas. 
Two previous large studies have shown the ability of trained family physicians to perform colonoscopy competently and safely. In a series of 1,048 procedures reported by Hopper and colleagues, ${ }^{7}$ a cecal intubation rate of $93 \%$ in medicated patients was achieved, with an adenoma detection rate of $43.8 \%$. The second series of 750 procedures, reported by Pierzchajlo et al ${ }_{1}^{8}$ had a cecal intubation rate of $91.5 \%$ and an adenoma detection rate of $17.8 \%$. Three additional smaller case series describe the colonoscopy experience of family physicians. ${ }^{9-11}$

The purpose of the current study was to verify that 2 trained rural family physicians could perform colonoscopy competently and safely in an outpatient office setting

\section{METHODS}

We undertook a retrospective case review of 731 colonoscopy procedures performed in a rural family practice office endoscopy suite. All patients were referred from within the practice, and all procedures were performed by the 2 physician authors. Detailed informed consent was obtained before the procedure. Standard colon preparations were accomplished with either $4 \mathrm{~L}$ of oral polyethylene glycol or phosphosoda solution. Patients underwent monitored conscious sedation with intravenous diazepam and meperidine or midazolam and meperidine.

Cold biopsy removal of polyps was performed at the time of the colonoscopy. Patients with larger polyps $(>10 \mathrm{~mm})$ requiring snare polypectomy were referred to a gastroenterologist. Biopsies were performed of large lesions and masses, and the patients were referred for colorectal surgery.

The Institutional Review Board at East Carolina University gave approval for this study, with patients being identified by a number only in the database.

An anonymous patient satisfaction questionaire developed by the authors was mailed to the 571 patients undergoing an initial colonoscopy; 281 patients $(49.2 \%)$ responded. They were asked to rate their procedure experience on a 10 -point scale, with 0 being the worst experience and 10 being the best possible experience. Patients were asked to respond with yes or no to indicate whether they would return to the office for a repeat colonoscopy.

Data was extracted from procedure notes and entered into a SPSS (Statistical Package for the Social Sciences, SPSS, v. 11.5) database program. Descriptive statistics were used to characterize the study population. We used $\chi^{2}$ analysis to determine the statistical significance of the difference in cecal intubation rates between 1996-1998 and 1999-2001.
Table 1. Indications for Colonoscopy and Adenomatous Polyp Yield by Indication ( $\mathrm{N}=731)$

\begin{tabular}{lcc}
\hline Indication* & $\%$ (No.) & $\begin{array}{c}\text { With Adenomas }{ }^{\dagger} \\
\% \text { (No.) }\end{array}$ \\
\hline Previous polyps & $22.2(229)$ & $32.3(74)$ \\
Rectal bleeding & $19.8(204)$ & $16.7(34)$ \\
Family history of & $10.5(108)$ & $18.5(20)$ \\
$\quad$ colon cancer & $10.0(103)$ & $15.5(16)$ \\
Abdominal pain & $9.3(96)$ & $17.7(17)$ \\
Screening & & $25.4(17)$ \\
Heme-positive stool & $6.5(67)$ & $14.0(6)$ \\
Iron deficiency & $4.2(43)$ & $15.0(6)$ \\
Constipation & $3.9(40)$ & $25.6(10)$ \\
Change in bowel habits & $3.8(39)$ & $17.9(5)$ \\
Chronic diarrhea & $2.7(28)$ & $0.0(0)$ \\
Weight loss & $0.3(3)$ & - \\
Other & $6.2(64)$ & - \\
Nonspecified & $0.7(7)$ & \\
\hline * Some patients had more than 1 indication. & \\
$\dagger$ & Villous adenomas and adenomatous polyps are considered together as adenomas. \\
キ The relatively low percentage of screening studies is attributed to Medicare cov- \\
erage for screening colonoscopy not occurring until 2000, late in the case series.
\end{tabular}

Both physician authors trained in US family medicine residencies and were credentialed to do flexible sigmoidoscopy in 1979 and 1982. In 1994, the practice purchased a colonoscope, and a number of complete colonoscopies were performed in unsedated patients. In 1996, each physician attended a formal course on colonoscopy. Their referral gastroenterologist initially proctored them when performing colonoscopy in the office.

\section{RESULTS}

Demographic data on the patients showed that $48.4 \%$ were male and $51.6 \%$ were female. Mean age was 62.7 years with a range of 20 to 92 years. There were 571 initial colonoscopies and 160 follow-up examinations for a total of 731 colonoscopies. All follow-up examinations were performed for polyp surveillance at 1 - to 3 -year intervals. Repeat examinations showed good correlation with the initial colonoscopy, and no major pathologic lesion was missed on the first examination.

Indications are summarized in Table 1 . The most common indications were previous polyps (22.2\%), rectal bleeding $(19.8 \%)$, family history of colon cancer $(10.5 \%)$, abdominal pain (10\%), and screening (9.3\%). Some procedures had multiple indications.

Drug dosages for medications used in conscious sedation were averaged. The mean doses were $4.6 \mathrm{mg}$ of diazepam, $43.4 \mathrm{mg}$ of meperidine, and $2.6 \mathrm{mg}$ of midazolam.

Cecal intubation rates were averaged by dates 1996-1998 and 1999-2001 and by the overall rate for 
all procedures. The cecal intubation rate was $89.5 \%$ (229 of 256) from 1996-1998, and 94.6\% (442 of 467) from 1998-2001. The overall rate for the entire series was $92.8 \%$ (671 of 723 ). These data suggest a statistically significant training effect between the earlier and later periods. $\left(\chi^{2}=6.682, P=.008\right)$ Air-contrast barium enema was offered to all patients whose examination did not reach the cecum.

Supplememtal Appendix 1 (available online only

at http://www.annfammed.org/cgi/content/

full full/3/2/122/DC1) summarizes the major pathologic findings determined by biopsy of 731 colonoscopy specimens. There were 215 adenomatous polyps found as a result of 156 procedures, for a $21.3 \%$ incidence. Villous adenomas were found in $3.1 \%$ (23) of cases. Six adenocarcinomas were found in $0.8 \%$ of cases.

Analysis of adenomatous polyp yield by each indication is summarized in Table 1 . The highest yield indication was previous colon polyps, with $32.3 \%$ showing adenomas.

Supplememtal Appendix 2 (available online only

at http://www.annfammed.org/cgi/content/ full/3/2/122/DC1) summarizes data of adenomatous polyp yield by age and sex. Most notably, men older than 50 years had a higher incidence of adenomas $(27.2 \%)$ compared with women older than 50 years $(21.4 \%)$. This result approaches statistical significance $(P=.081)$.

Table 2 displays the distribution of adenomatous polyps by location in the colon. Fifty-six percent of polyps were in the transverse or ascending colon or the cecum, locations which are beyond the reach of the flexible sigmoidoscope. Only 24\% of patients with these proximal polyps had concurrent polyps in the descending colon or below.

Nineteen patients $(2.6 \%)$ were referred to a gastroenterologist for removal of polyps larger than $1 \mathrm{~cm}$. Findings of the repeated examination correlated highly with those of the original examination, and the pathologic findings were confirmed in all cases. There were 5 cases $(26 \%)$ in which the gastroenterologist found an additional small polyp on repeated colonoscopy, an outcome consistent with previous findings from the gastroenterology literature in which 1 study showed a $24 \%$ additional adenoma detection rate on an immediate second colonoscopy. ${ }^{12}$

Ten patients $(1.4 \%)$ were referred to a colorectal surgeon for resection of either a large villous adenoma or adenocarcinoma. Supplemental Appendix 3 (available online only at http://www.annfammed.org/cgi/

content/full/3/2/122/DC1) describes these cases in more detail with follow-up information. Again pathologic findings correlated with the original examination in all cases.
Table 2. Distribution of Adenomas Detected $(\mathrm{N}=731)$

\begin{tabular}{lcc}
\hline Location & Number & Percent \\
\hline Cecum & 24 & 10.1 \\
Ascending colon & 50 & 21.0 \\
Hepatic flexure & 14 & 5.9 \\
Transverse colon & 45 & 18.9 \\
Splenic flexure & 5 & 2.1 \\
Descending colon & 24 & 10.1 \\
Sigmoid colon & 38 & 16.0 \\
Rectosigmoid junction & 5 & 2.1 \\
Rectum & 33 & 13.8 \\
Totals & 238 & 100.0 \\
\hline
\end{tabular}

Note: Adenomas include both adenomatous polyps and villous adenomas. Only $24 \%$ of patients with adenomas proximal to the splenic flexure also had concurrent polyps in the descending colon or below.

The complication rate for this series was very low. Four patients $(0.54 \%)$ experienced bradycardia and hypotension, which responded promptly to intravenous normal saline infusion and atropine. One patient developed atrial fibrillation and required antiarrhythmic therapy with a good outcome. One patient (0.14\%) had bleeding after polypectomy and required an overnight hospital observation without the need for transfusion or surgery. No colon perforations occurred in this series.

A patient satisfaction questionaire was received from 281 patients who had undergone office colonoscopy. Ninety percent rated their experience as 7 to 10 on a 10 -point scale. The mean score was 8.8 . Ninetytwo percent said they would have another examination in the family medicine office.

\section{DISCUSSION}

This study contributes additional knowledge and reassurance as to the quality and safety of colonoscopy performed in an outpatient family medicine office setting. Our study also found that pathologic findings of the 29 cases in which the patients were referred to specialty care correlated highly with those of the original examination. Additionally, patients reported a high level of satisfaction with their primary physician performing the procedure in a familiar setting. To our knowledge, this level of satisfaction has not been previously reported in the family medicine literature. A current report ${ }^{13}$ notes similar patient satisfaction of $90 \%$ with virtual colonoscopy.

In a recent publication the US Multi-Society Task Force on Colorectal Cancer, which excluded family physicians from participation, reviewed the recommendations for quality improvement in the performance of colonoscopy. ${ }^{14}$ These recommendations included target goals of cecal intubation rates of $90 \%$ or greater 
for all examinations and $95 \%$ or greater for screening examinations. Target goals for adenoma detection for patients undergoing first-time colonoscopy should be $25 \%$ or greater for men and $15 \%$ or greater for women older than 50 years. The current study shows that the 2 family physician colonoscopists met or exceeded each of these target goals for high-quality colonoscopy examinations. Another recent study of 69 gastroenterologists showed only $55 \%$ achieved a cecal intubation rate greater than $90 \%$, suggesting that the $90 \%$ target goal is too ambitious. ${ }^{15}$

Limitations of this study include evaluating only 2 family physicians performing colonoscopy in one practice. Larger prospective studies with more family physicians performing the procedure should be undertaken next. Ideally, a national electronic database on quality parameters from family-physician-performed colonoscopies should be initiated and maintained.

A second limitation of this study is that only cold biopsy ablation of polyps was performed, and patients who had polyps greater than $1 \mathrm{~cm}$ were referred for snare polypectomy. This approach was suggested by our referral gastroenterologist to reduce the risks of perforation associated with snare polypectomy. Only $2.6 \%$ of cases were referred for a second procedure. Certainly a strong argument can be made that family physicians should perform snare polypectomy to eliminate the need for a second procedure.

A substantial percentage of family physicians can and should be trained to perform colonoscopy, ${ }_{1}^{16,17}$ especially those who will practice in rural underserved areas that have no local gastroenterologist. This training would improve not only access to colonoscopic care but also compliance rates for screening colonoscopy. Additional benefits include increased cost efficiency by doing these procedures in an outpatient office setting.

More research needs to be done on training physicians to perform colonoscopy. ${ }^{18,19}$ Forty-six percent of family medicine training programs offer colonoscopy training ${ }_{1}^{19}$ and some programs have added a fourth fellowship year in advanced family medicine to allow training in colonoscopy and other procedures. Pursuing colonoscopy training requires an ongoing commitment to excellence, continuous quality improvement, and continuing medical education on this subject. Those family physicians willing to accept this challenge can provide additional valuable medical services to their communities and can contribute to the improved health of their patient population.

To read or post commentaries in response to this article, see it online at http://www.annfammed.org/cgi/content/full/3/2/122.

Key words: Colonoscopy, outpatient; ambulatory care; rural health services; family practice
Submitted April 12, 2004; submitted, revised, October 12, 2004; accepted October 26, 2004.

Acknowledgment: We thank Suzanne Kelly for her help in the data analysis of this study.

\section{References}

1. Walsh JME, Terdiman JP. Colorectal cancer screening - scientific review. JAMA. 2003;289:1228-1296.

2. Walsh JME, Terdiman JP. Colorectal cancer screening - clinical applications. JAMA. 2003;289:1297-1302.

3. Lieberman DA, Rex DK. Feasibility of colonoscopy screening: discussion of issues and recommendations regarding implementation. Gastroint Endosc. 2001;54:662-667.

4. American Academy of Family Physicians Practice Profile I and II survey, May 2002. Leawood, Kan: American Academy of Family Physicians. 2002.

5. Ackermann RJ. Performance of gastrointestinal tract endoscopy by primary care physicians - lessons from the US Medicare database. Arch Fam Med. 1997;6:52-58.

6. Worthington DV, for the American Academy of Family Physicians. Colonoscopy: procedural skills. Ann Fam Phys. 2000;62:1-12.

7. Hopper W, Kyker KA, Rodney WM. Colonoscopy by a family physician: a 9 year experience of 1,048 procedures. J Fam Pract. 1996;43:561-566.

8. Pierzchajlo RPJ, Ackerman RJ, Vogel RL. Colonoscopy performed by a family physician. A case series of 751 procedures. J Fam Pract. 1997;44:473-480.

9. Rodney WM, Dabov G, Cronin C. Evolving colonoscopy skills in a rural family practice: the first 293 cases. Fam Pract Res J. 1993; 13:43-52.

10. Carr KW, Worthington M, Rodney WM, Gentry S, Sellers A, Sizemore J. Advancing from flexible sigmoidoscopy to colonoscopy in rural family practice. Tenn Med Assoc J. 1998;91:21-26.

11. Godreau CJ. Office-based colonoscopy in a family practice. Fam Pract Res J. 1992;12:313-320.

12. Rex DK, Cutler CS, Lemmel GT. Colonoscopic miss rates of adenomas determined by back to back colonoscopies. Gastroenterology. 1997; 112:24-28.

13. Pickhardt PJ, Choi JR, Hwang I, et al. Computed tomographic virtual colonoscopy to screen for colorectal neoplasia in asymptomatic adults. New Engl J Med. 2003;349:2191-2200.

14. Rex DK, Bond JH, Winawer $S$, et al. Quality in the technical performance of colonoscopy and the continuous quality improvement process for colonoscopy: recommendations of the U.S. Multi-Society task force on colorectal cancer. Am J Gastroenterol. 2002;97:1296-1308.

15. Cotton PB, Conner P, McGee D et al. Colonoscopy: practice variation among 69 hospital based endoscopists. Gastrointest Endoscopy. 2003;57:352-357.

16. Rodney WM. Will virtual reality simulators end the credentialing arms race in gastrointestinal endoscopy or the need for family physician faculty with endoscopic skills? Am J Board Fam Pract. 1998;11:492-496.

17. Harper MB, Pope JB, Mayeaux EJ, Davis TJ, Myers A, Lirette A. Colonoscopy experience at a family practice residency: a comparison to gastroenterology and general surgery services. Fam Med. 1997;29:575-579.

18. Freeman M. Training and competence in gastrointestinal endoscopy. Rev Gastroenterol Disord. 2001;1:73-86.

19. Wilkins T, Jester D, Kemrick J, Dahl J. The current state of colonoscopy training in family medicine residency programs. Fam Med. 2004;36:407-411. 